\title{
On the Uncertainty About the Total Economic Impact of Climate Change
}

\author{
Richard S. J. Tol
}

Accepted: 12 February 2012 / Published online: 26 February 2012

(C) The Author(s) 2012. This article is published with open access at Springerlink.com

\begin{abstract}
This paper uses a vote-counting procedure to estimate the probability density function of the total economic impact as a parabolic function of global warming. There is a wide range of uncertainty about the impact of climate change up to $3^{\circ} \mathrm{C}$, and the information becomes progressively more diffuse beyond that. Warming greater than $3^{\circ} \mathrm{C}$ most likely has net negative impacts, and warming greater than $7^{\circ} \mathrm{C}$ may lead to a total welfare loss. The expected value of the social cost of carbon is about $\$ 29 / \mathrm{tC}$ in 2015 and rises at roughly $2 \%$ per year.
\end{abstract}

Keywords Climate change $\cdot$ Economic impact $\cdot$ Meta-analysis $\cdot$ Social cost of carbon

JEL Classification Q54

\section{Introduction}

Greenhouse gas emissions generally accepted as one of the largest externalities of our times. However, the impact of climate change on human welfare is poorly understood. Some argue that climate change would have devastating consequences (Stern et al. 2006) while others

R. S. J. Tol (凶)

Department of Economics, University of Sussex, Brighton, UK

e-mail: r.tol@sussex.ac.uk

R. S. J. Tol

Institute for Environmental Studies, Vrije Universiteit, Amsterdam, The Netherlands

R. S. J. Tol

Department of Spatial Economics, Vrije Universiteit, Amsterdam, The Netherlands

R. S. J. Tol

Mantell Building, University of Sussex, Falmer BN1 9RF, UK 
conclude that climate change is a minor nuisance (Mendelsohn et al. 2000a). In this paper, I use the available estimates in the literature to assess the uncertainty about the total economic impact of climate change.

In previous papers (Tol 2005, 2008, 2009, 2010), I assess the uncertainty about the marginal impact of carbon dioxide emissions. This is relatively straightforward as there are now more that 300 estimates of the social cost of carbon. However, there are only 14 estimates of the total impact of climate change. ${ }^{1}$ Therefore, as a second contribution, this paper offers a method to estimate objectively a probability density function with few data. As there is no repeated experiment, and indeed the impact of climate has yet to be observed, this probability density function describes the degrees of belief - or rather inter-subjective belief.

The method is not particularly complicated or advanced. It uses basic probability and statistical theory but applies it in an unconventional way. The main concern is that standard methods, such as Bayesian updating, lead to overconfidence as outliers are discounted. The method used here respects the weak empirical basis (14 estimates) that implies a wide range of uncertainty, which grows with extrapolation.

The paper proceeds as follows. Section 2 surveys the literature on the total economic impact of climate change. Section 3 takes the 14 static point estimates and turns them into a probability density function of the dynamic impacts. Section 4 derives the implied social cost of carbon. Section 5 concludes.

\section{Estimates of the Total Economic Effect of Climate Change}

The first study of the global welfare impacts of climate change was done by Fankhauser (1994, 1995). Table 1 lists that study and a dozen other studies of the worldwide effects of climate change.

Any study of the economic impact of climate change begins with some assumptions on future emissions, the extent and pattern of warming, and other possible aspects of climate change, such as sea level rise and changes in rainfall and storminess. The studies must then translate from climate change to economic consequences. A range of methodological approaches are possible. Nordhaus (1994a) interviewed a limited number of "experts", 2 asking them directly about the total economic impact.

The studies by Fankhauser (1994, 1995); Nordhaus (1994b); Tol (1995, 2002a,b) use the enumerative method. In this approach, estimates of the "physical effects" of climate change are obtained one by one from natural science papers, which in turn may be based on some combination of climate models, impact models and laboratory experiments. The physical impacts must then each be given a price, and added up. For traded goods and services, such as agricultural products, agronomy papers are used to predict the effect of climate on crop yield, and then market prices or economic models are used to value that change in farm productivity. As another example, the impact of sea level rise constitutes the costs of coastal protection and land lost, estimates of which can be found in the engineering literature; the economic input in this case is not only the cost of dike building and the value of land, but also decisions about which properties to protect. For non-traded goods and services, other

\footnotetext{
1 The social cost of carbon depends on the total impact of climate change as well as on assumptions on scenarios (emissions, climate, population, economic development, technology), discount rate, risk aversion, inequity aversion, and vulnerability. Thus, two handfuls of total impact estimates imply hundreds of estimates of the marginal impact.

2 While these people were experts in other fields, there was no literature on the economic impacts of climate change at that time.
} 
Table 1 Estimates of the welfare loss due to climate change (as equivalent income loss in percent)

\begin{tabular}{|c|c|c|}
\hline \multirow[t]{2}{*}{ Study } & Warming & Impact \\
\hline & $\left({ }^{\circ} \mathrm{C}\right)$ & (\%GDP) \\
\hline Nordhaus (1994b) & 3.0 & -1.3 \\
\hline Nordhaus (1994a) & 3.0 & $\begin{array}{l}-4.8 \\
(-30.0 \text { to } 0.0)\end{array}$ \\
\hline Fankhauser (1995) & 2.5 & -1.4 \\
\hline Tol (1995) & 2.5 & -1.9 \\
\hline Nordhaus and Yang (1996) ${ }^{\mathrm{a}}$ & 2.5 & -1.7 \\
\hline Plamberk and Hope (1996) ${ }^{\mathrm{a}}$ & 2.5 & $\begin{array}{l}-2.5 \\
(-0.5 \text { to }-11.4)\end{array}$ \\
\hline Mendelsohn et al. $(2000 \mathrm{a})^{\mathrm{a}, \mathrm{b}, \mathrm{c}}$ & 2.5 & $\begin{array}{l}0.0^{b} \\
0.1^{b}\end{array}$ \\
\hline Nordhaus and Boyer (2000) & 2.5 & -1.5 \\
\hline Tol (2002a) & 1.0 & $\begin{array}{l}2.3 \\
(1.0)\end{array}$ \\
\hline Maddison $(2003)^{\mathrm{a}, \mathrm{d}}$ & 2.5 & -0.1 \\
\hline Rehdanz and Maddison $(2005)^{\mathrm{a}, \mathrm{c}}$ & 1.0 & -0.4 \\
\hline Hope $(2006)^{\mathrm{a}, \mathrm{e}}$ & 2.5 & $\begin{array}{l}0.9 \\
(-0.2 \text { to } 2.7)\end{array}$ \\
\hline (Nordhaus 2006) & 2.5 & $\begin{array}{l}-0.9 \\
(0.1)\end{array}$ \\
\hline
\end{tabular}

Estimates of the uncertainty are given in bracket as standard deviations or 95\% confidence intervals

a Note that the global results were aggregated by the current author

b The top estimate is for the "experimental" model, the bottom estimate for the "cross-sectional" model

c Mendelsohn et al. only include market impacts

$\mathrm{d}$ Maddison only considers non-market impacts on households

e The numbers used by Hope are averages of previous estimates by Fankhauser (1995) and Tol (2002a);

Stern et al. (2006) adopt the work of Hope

methods are needed. An ideal approach might be to study how climate change affects human welfare through health and nature in each area around the world, but a series of "primary valuation" studies of this kind would be expensive and time-consuming. Thus, for enumerative studies, the monetisation of non-market climate change impacts relies on benefit transfer, in which epidemiology papers are used to estimate effects on health or the environment, and then economic values are applied from studies of the valuation of mortality risks in other contexts than climate change.

The statistical approach is an alternative (Mendelsohn et al. 2000a,b). It is based on direct estimates of the welfare impacts, using observed variations (across space within a single country) in prices and expenditures to discern the effect of climate. Mendelsohn assumes that the observed variation of economic activity with climate over space holds over time as well; and uses climate models to estimate the future impact of climate change. Mendelsohn's estimates are done per sector for selected countries, extrapolated to other countries, and then added up, but physical modelling is avoided. Other studies (Maddison 2003; Nordhaus 2006) use versions of the statistical approach as well. Nordhaus uses empirical estimates of the aggregate climate impact on income across the world (per grid cell), while Maddison looks at 
patterns of aggregate household consumption (per country). Like Mendelsohn, Nordhaus and Maddison rely exclusively on observations, assuming that "climate" is reflected in incomes and expenditures - and that the pattern of impact of variation of climate over space is the same as the pattern of impact of variation of climate over time. Rehdanz and Maddison (2005) also empirically estimate the aggregate impact, using self-reported happiness for dozens of countries.

The enumerative approach has the advantage that it is based on natural science experiments, models and data; the results are physically realistic. However, the enumerative approach also raises concerns about extrapolation: economic values estimated for other issues are applied to climate change concerns; values estimated for a limited number of locations are extrapolated to the world; and values estimated for the recent past are extrapolated to the remote future. Tests of benefit transfer methods have shown time and again that errors from such extrapolations can be substantial (Brouwer and Spaninks 1999). But perhaps the main disadvantage of the enumerative approach is that the assumptions about adaptation may be unrealistic — as temperatures increase, presumably private and public-sector reactions would occur to both market and non-market events.

In contrast, the statistical approach relies on natural experiments and on spatial and temporal analogues. These estimates have the advantage of being based on real-world differences in climate and income, rather than extrapolated differences. Therefore, adaptation is realistically, if often implicitly, modelled. However, statistical studies run the risk of mis-attribution to climate. Furthermore, the data often allow for cross-sectional studies only; and some important aspects of climate change, particularly the direct impacts of sea level rise and carbon dioxide fertilization, do not have much spatial variation.

Given that the studies in Table 1 use different methods, it is striking that the estimates are in broad agreement on a number of points. Table 1 shows selected characteristics of the published estimates. The first column of Table 1 shows the underlying assumption of warming, measured as the increase in the global average surface air temperature. The impact studies in Table 1 are comparative static; they ignore the effects of climate change on economic growth, they impose a future climate on today's economy, and they assume instantaneous adaptation. One can therefore not attach a date to these estimates. The second column of Table 1 shows the impact on welfare at that future time, expressed as a percentage of income. For instance, (Nordhaus 1994b) estimates that the impact of $3^{\circ} \mathrm{C}$ global warming is as bad as losing $1.4 \%$ of income. In some cases, a confidence interval (usually at the $95 \%$ level) appears under the estimate; in other cases, a standard deviation is given; but most studies do not report any estimate of the uncertainty.

A first area of agreement between these studies is that the welfare effect of a doubling of the atmospheric concentration of greenhouse gas emissions on the current economy is relatively small —a few percentage points of GDP. It is roughly equivalent to a year's growth in the global economy - as the estimates in Table 1 are the impacts of a century or so of climate change, the economic loss from climate change is not all that large. However, the damage is not negligible. An environmental issue that causes a permanent reduction of welfare, lasting into the indefinite future, would certainly justify some steps to reduce such costs.

A second finding is that some estimates (Hope 2006; Mendelsohn et al. 2000a,b; Tol $2002 \mathrm{~b}$ ) point to initial benefits of a modest increase in temperature, followed by losses as temperatures increase further. There are no estimates of costs for a warming above $3^{\circ} \mathrm{C}$, although climate change may well go beyond that. All studies published after 1995 have regions with net gains and net losses due to global warming, while earlier studies only find net losses. Figure 1 illustrates this pattern. The horizontal axis shows the increase in average global temperature. The vertical index shows the central estimate of welfare loss. The central 


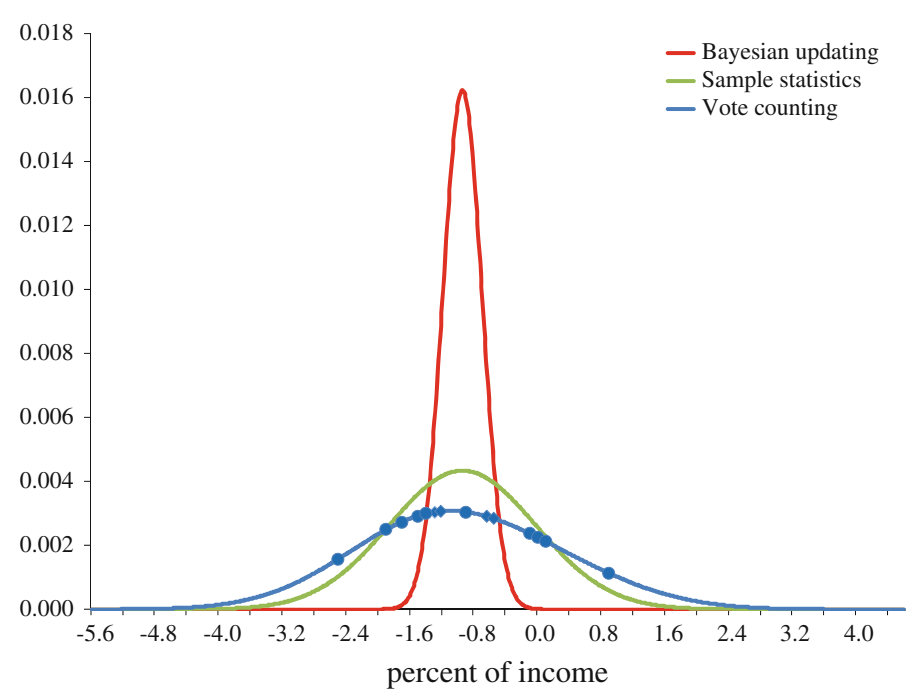

Fig. 1 Three alternative probability density functions of the total economic impact of $2.5^{\circ} \mathrm{C}$ warming; the dots are the 10 primary estimates; the diamonds the impacts extrapolated from the primary estimates for 1.0 and $3.0^{\circ} \mathrm{C}$ of warming

line shows a best-fit parabolic line from an ordinary least squares regression. Of course, it is something of a stretch to interpret the results of these different studies as if they were a predictive time-series of how climate change will affect the world economy over time, and so this graph should be interpreted more as an interesting calculation than as hard analysis. But the pattern of modest economic gains due to climate change, followed by substantial losses, appears also in the few studies that report likely impacts over time (Mendelsohn et al. 2000a,b; Nordhaus and Boyer 2000; Smith et al. 2001; Tol 2002b).

The initial benefits arise partly because more carbon dioxide in the atmosphere reduces "water stress" in plants and may make them grow faster (Long et al. 2006). In addition, the output of the global economy is concentrated in the temperate zone, where warming reduces heating costs and cold-related health problems. Although the world population is concentrated in the tropics, where even the initial effects of climate change are probably negative, the relatively smaller size of the economy in these areas means that gains for the high-income areas of the world more than offset losses in the low-income areas. However, even though, initially, net economic impacts may well be positive, it does not follow that greenhouse gas emissions should be subsidized. The climate responds rather slowly to changes in greenhouse gas emissions. The initial warming can no longer be avoided; it should be viewed as an inevitable "sunk" benefit.

Third, the uncertainty is vast. For example, consider only the studies that are based on a benchmark warming of $2.5^{\circ} \mathrm{C}$. These studies have an average estimated effect of climate change on average output of $-0.7 \%$ of GDP, and a standard deviation of $1.2 \%$ of GDP. Only five of the 14 studies in Table 1 report some measure of uncertainty. Two of these report a standard deviation only — which suggests symmetry in the probability distribution. Three studies report a confidence interval — of these, two studies find that the uncertainty is right-skewed, but one study finds a left-skewed distribution. Although the evidence on uncertainty here is modest and inconsistent, it seems that undesirable surprises are more likely than desirable surprises. While it is relatively easy to imagine a disaster scenario for climate change-for 
example, involving massive sea level rise or monsoon failure that could even lead to mass migration and violent conflict-it is not easy to imagine that climate change will be a huge boost to human welfare.

The kinds of studies presented in Table 1 can be improved in numerous ways, some of which have been mentioned already. In all of these studies, economic losses are approximated with direct costs, ignoring general equilibrium and even partial equilibrium effects. There may be some overlap between impact estimates-for example, losses in water resources and losses in agriculture may actually represent the same loss. Estimates are often based on extrapolation from a few detailed case studies, and extrapolation is to climate and levels of development that are very different from the original case study. Realistic modelling of adaptation is problematic, and studies typically either assume no adaptation or perfect adaptation. Willingness to pay (WTP) is the basis for valuation, but as climate change is an involuntary risk imposed by a previous generation, willingness to accept compensation (WTA) cannot be ruled out as a more appropriate basis. Essentially, the estimates surveyed here reflect the WTP for a better climate.

Many effects are unquantified, and some of these may be large. The effects of climate change that have been quantified and monetized include the impacts on agriculture and forestry, water resources, coastal zones, energy consumption, air quality, tropical and extratropical storms, and human health. Obviously, this list is incomplete. Even within each category, the assessment is incomplete. Many of the omissions seem to be relatively small-such as saltwater intrusion, cooling water, fisheries, wind and wave energy, Arctic navigation and exploitation, disruptions of traffic and construction. There are large unknowns too: extreme climate scenarios, the very long term, biodiversity loss, the possible effects of climate change on economic development and even political violence.

Examples of extreme climate scenarios include an alteration of ocean circulation patterns and the disintegration of major ice sheets. Exactly what would cause these sorts of changes or what effects they would have are not at all well-understood but the costs could be substantial. Another big unknown is the effect of climate change in the very long term. Most static analyses examine the effects of doubling the concentration of atmospheric $\mathrm{CO}_{2}$; most studies looking at effects of climate change over time consider only the time period up until 2100. Of course, climate change will not suddenly halt in 2100. In fact, most estimates suggest that the negative effects of climate change will grow, and even accelerate, in the years up to 2100. Climate change could have a profound impact on biodiversity, not only through changes in temperature and precipitation, but in the ways climate change might affect land use and nutrient cycles, ocean acidification, and the prospects for invasion of new habitats by alien species. However, there are few quantitative studies of the effects of climate change on ecosystems and biodiversity and valuation of ecosystem change is difficult, particularly if that change is not marginal. There is an open question about the possible effects of climate change on annual rates of economic growth. Accumulated over a century or more, even a small impact of the growth rate would dominate all earlier estimates of the economic effects of climate change.

\section{The Uncertainty About the Total Costs of Climate Change}

\subsection{Methods}

Table 1 has 14 estimates of the total costs of climate change. Ten of those are comparable as they refer to the same warming, while two estimates consider less warming and two estimates 
greater warming. In order to reconcile the estimates and assess the uncertainty, the following procedure was followed.

First, a parabola was fitted, through least squares, to the 14 observations. The result is the central line shown in Fig. 3. Initial warming has positive effects-associated with carbon dioxide fertilization, reduced winter heating costs, and lower cold-related mortality and morbidity - but beneficial impacts reach their peak at a warming $1.1^{\circ} \mathrm{C}$ and fall thereafter to turn negative at $2.2^{\circ} \mathrm{C}$. As the world is committed to one and probably two degrees of warming (Clarke et al. 2009), the initial benefits are sunk benefits: The net benefits of climate change will be reaped regardless of climate policy. The incremental impacts of the climate change than can be avoided are negative.

This single parabola may be the best guess of the impacts of climate change, but it does not reflect the uncertainty. Below, I construct a set of alternative impact curves and estimate their probability.

To that end, second, 14 parabolas were fitted to all but one of the observations (single bootstrap); and 91 parabolas were fitted to all but two of the observations (double bootstrap). Third, 44 parabolas were fitted that exactly go through two of the observations (double fit). ${ }^{3}$ Fourth, 14 parabolas were fitted that exactly go through one of the observations and minimise the squared deviation with the remaining 13 observations (single fit).

Thus, a total of 164 parabolas were fitted. These parabolas span a wide range of results, but this range does not reflect the true uncertainty. Among the 164, the most pessimistic parabola (in the long run) goes through the most optimistic estimate for $2.5^{\circ} \mathrm{C}$ and the most pessimistic estimate for $3.0^{\circ} \mathrm{C}$ - this is the steepest decline. The most optimistic parabola (in the long run) goes through the most pessimistic estimate for $2.5^{\circ} \mathrm{C}$ and the most optimistic estimate for $3.0^{\circ} \mathrm{C}$ - this is the steepest incline. That is, the range of point estimates in Table 1 is treated as the range of uncertainty. A zero probability is assigned to impacts that are larger or smaller than those shown in Table 1. Put differently, the uncertainty about the point estimates is ignored.

I therefore construct a probability density function (PDF) for the total impact of climate change at $1.0,2.5$ and $3.0^{\circ} \mathrm{C}$ warming. This is readily done with the 10 observations for $2.5^{\circ} \mathrm{C}$, but there are only 2 observations each for 1.0 and $3.0^{\circ} \mathrm{C}$. Therefore, I use the parabolas that exactly go through one estimate while minimising the squared distance with the remaining 13 estimates (method 4, single fit, above). This procedure exactly reproduces one of the primary estimates and treats the other 13 equally. Thus, there are 14 "observations" for each scenario.

There are various PDFs that can be constructed from 14 point estimates. (1) One can assume Normality and use the sample statistics, but this ignores the uncertainty about the point estimates. $(2,3)$ One can use the sample standard deviation and assign this uncertainty to each of the point estimates. The 14 individual PDFs can be then combined using (2) Bayesian updating or (3) vote-counting. Mathematical details are given in the appendix. As vote-counting gives the widest range of uncertainty, I prefer this method. Bayesian updating is the more appropriate method if the 14 estimates are repeated observations of the same. However, if there are irreconcilable differences between the estimates-because different impacts were included, different valuation methods used, or different ways to aggregate over time, between people, and across potential states of the world - then vote-counting is more appropriate (Freeman and Groom 2010).

From each of the 3 PDFs (one each for $1.0,2.5$ and $3.0^{\circ} \mathrm{C}$ ), 9 points were selected: the $1 \mathrm{st}$, 5th, 10th, 33rd, 50th, 67th, 90th, 95th, and 99th percentile (see Table 2). Picking one point

3 As the assumed warming is the same for many of the studies, many of the 182 combinations are infeasible. 
each from two out of three PDFs, $(2+1) \times 9 \times 9=243$ combinations of impact estimates result. I exactly fit a parabola to each of these 243 combinations of two "observations". The result is a set of parabolas that gives a wide range of results. The range is not inconsistent with the population of 14 primary studies.

A total number of 407 parabolas is the result (cf. Fig. 3). These parabolas are not equally plausible. Indeed, I oversampled the tails of the distribution. Each of the parabolas was given a likelihood equal to the increment of the Cumulative Distribution Function (CDF) derived above for the impact at $1.0,2.5$ and $3.0^{\circ} \mathrm{C}$. The probability of each parabola follows from adding the three probabilities and guaranteeing that the 407 probabilities sum to one. Adding (vote-counting) probabilities again leads to a wider and therefore more appropriate range of uncertainty than multiplying probabilities. Furthermore, as all 14 observations were each used in the construction of each of the three PDFs, multiplying the probabilities would imply that the same information is used thrice.

Two alternative probability assignments were used as a sensitivity analysis. First, I compute the sum of squared deviations of the parabolas from the 14 observations. From that follows the prediction error (assuming 12 degrees of freedom as 2 parameters are estimated), and the likelihood (assuming a normal distribution). Second, I compute the likelihood of the parabolas using the 14 observations as the mean and the sample standard deviation (cf. Table 2). These two methods lead to a narrower range of uncertainty; these are regression methods and can therefore be interpreted as Bayesian updating of information (rather than as vote-counting).

Furthermore, the sample of parabolas is not random: I oversample in the centre and in the tails. I am not aware of a method to correct for importance sampling with the two alternative PDFs. In order to illustrate the impact, I use a fourth method, used in the sensitivity analysis below. The likelihood of each parabola equals the normalised sum of likelihoods according to the PDFs for the impact of $1.0,2.5$ and $3.0^{\circ} \mathrm{C}$ of warming.

\subsection{Results}

Figure 1 shows the PDF of the economic impact of $2.5^{\circ} \mathrm{C}$ warming. For comparison, the 10 observations are marked (by dots), as are the 4 extrapolated point estimates (by diamonds). The extrapolated estimates in fact fall in the middle of the distribution. Figure 1 also shows the PDF from Bayesian updating. It is very narrow, and in fact treats most of the observations as outliers. This is clearly inappropriate. Finally, Fig. 1 depicts the PDF based on the sample statistics. The two most extreme observations are at the 4.5 and $97.8 \%$ for the sample CDF and at the 11th and 92nd percentile for the vote-counting PDF. The sample frequency has the extrema at $1 /(2 * 14)=3.5$ and $96.5 \%$. The vote-counting PDF gives the widest range of uncertainty, and it is the only PDF that does not discount the probability of the largest point estimate. The vote-counting PDF is therefore used as the default PDF in the remainder of the paper.

Figure 7 shows the vote-counting PDFs for 1.0, 2.5 and $3.0^{\circ} \mathrm{C}$ of warming. These PDFs together imply a bivariate PDF for the parameters of the impact function (see above). This is displayed in Fig. 2. The bivariate distribution is the sum of three degenerated distributions, each with a small spread around what is almost a straight line in the parameter space. At the same time, the location on that line is much more uncertain. Figure 8 displays the modal lines and the modal probabilities of Fig. 2. While Fig. 1 shows that the economic impact of climate change within sample $\left(1.0-3.0^{\circ} \mathrm{C}\right)$ is reasonably well-constrained, Fig. 2 reveals

4 The derivative of the $\mathrm{CDF}$ is used rather than the PDF to correct for importance sampling. 


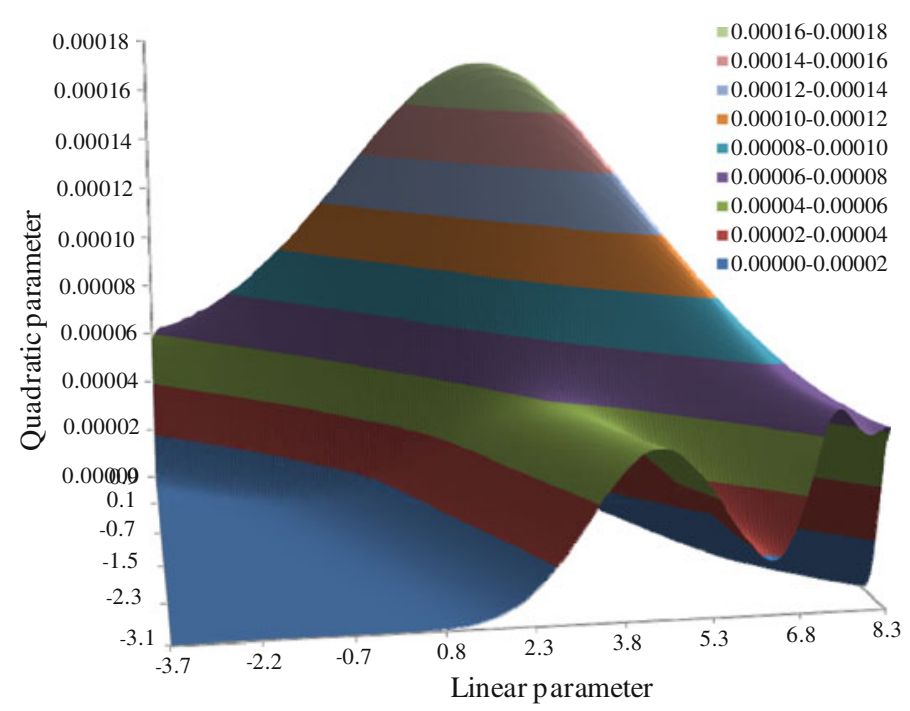

Fig. 2 The bivariate probability density function of the parameters of the impact parabola

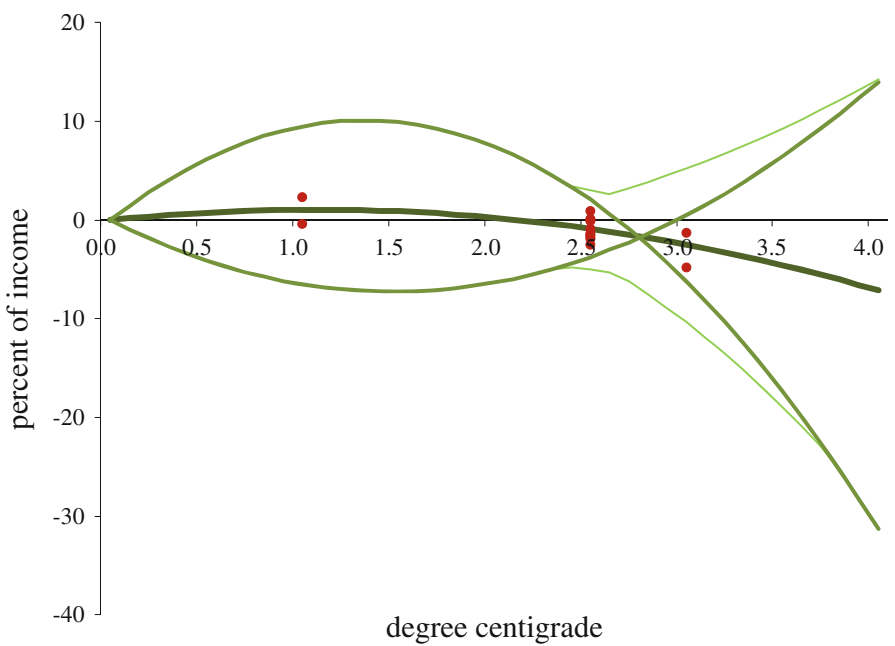

Fig. 3 The best-fit impact function (fat, centre line), the extreme impact functions, the extreme impacts (thin lines), and the primary impact estimates (dots)

that this information is consistent with a wide range of parameters, and hence with impacts outside sample $\left(>3.0^{\circ} \mathrm{C}\right)$.

Figure 3 shows the best fit parabola and the two extreme parabolas in the short run as well as in the long run (although minimum and maximum swap position). Figure 3 also shows the minimum and maximum across all parabolas. Figure 3 compares this to the 14 observations. By construction, the set of parabolas encompasses the observations. As Figs. 2, 3 show that the relatively tight evidence for the impacts of warming of up to $3.0^{\circ} \mathrm{C}$ implies a diffuse set of impacts beyond $3.0^{\circ} \mathrm{C}$. 


\section{$2^{\circ} \mathrm{C}$}

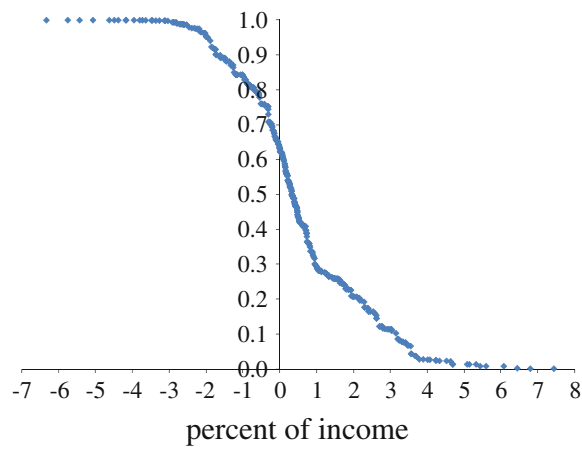

$5^{\circ} \mathrm{C}$

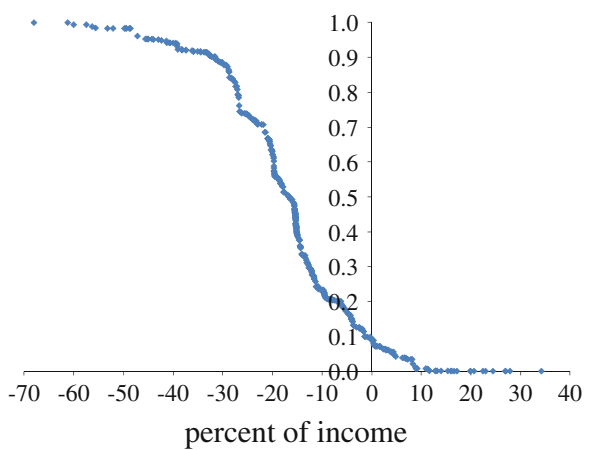

$3^{\circ} \mathrm{C}$

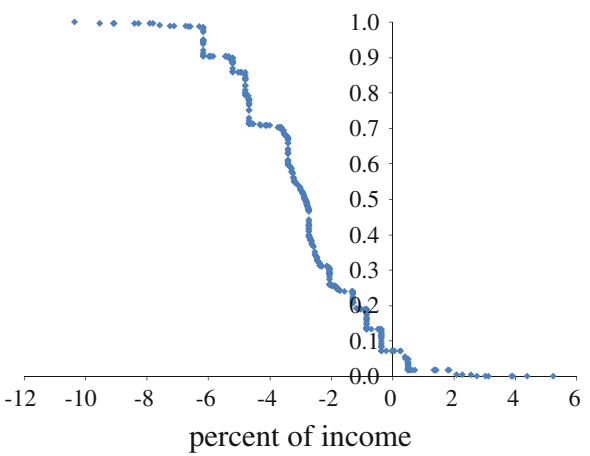

$10^{\circ} \mathrm{C}$

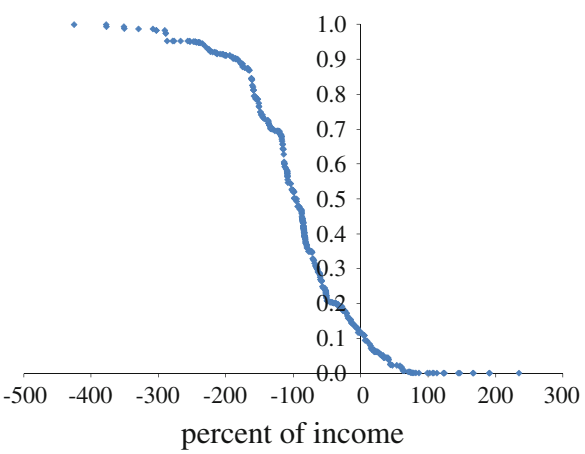

Fig. 4 The survival functions of the total economic impact of climate change for different degrees of global warming

73 of the 407 parabolas show positive impacts in the long run, but only $10 \%$ of the probability mass is assigned to this possibility. 26 of the 407 parabolas show negative impacts for any warming, but the probability is only $5 \%$. Therefore, the qualitative pattern suggested by the central curve in Fig. 3-net gains in the short run, net losses in the long run-is fairly robust.

Figure 4 shows the survival curves for the total impact at $2,3,5$ and $10^{\circ} \mathrm{C}$ warming. ${ }^{5}$ At $2^{\circ} \mathrm{C}$, the impact could be positive as well as negative. There is a probability of $37 \%$ of a net negative impact. This changes at $3{ }^{\circ} \mathrm{C}$. There is a probability of $93 \%$ of a net negative impact. At $5^{\circ} \mathrm{C}$, the impact lies with $90 \%$ probability between 4 and $-43 \%$ of income. At $10^{\circ} \mathrm{C}$, there is a $12 \%$ chance of positive impacts, while there is a $48 \%$ chance that the impact exceeds $-100 \%$ of income- that is, a total loss of welfare. ${ }^{6}$ The most pessimistic parabola in the sample hits a total welfare loss at $5.7^{\circ} \mathrm{C}$ warming.

\footnotetext{
5 Survival curves contain the same information as cumulative distribution functions, but are easier to read in this case.

6 Most people have reserves and assets that would prevent a total welfare loss in case their complete income is loss for a brief period. However, the impact functions are constructed such that a total income loss would be repeated, and indeed there would be desavings. I therefore put the threshold for a total welfare loss at $100 \%$ of the income. I did not knot the graphs at $-100 \%$ for reasons of clarity.
} 


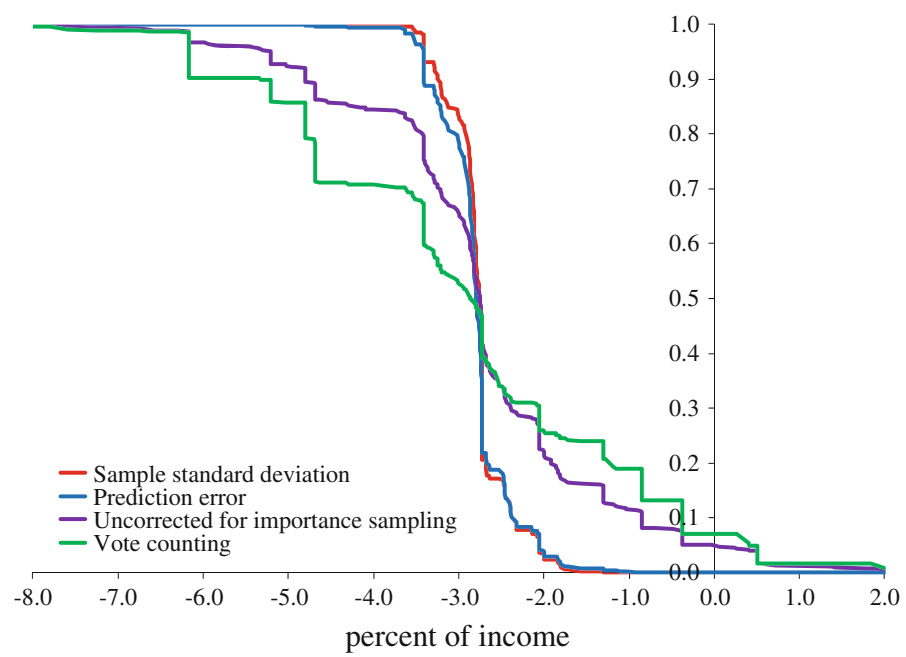

Fig. 5 Four alternative survival functions for the total economic impact of $3^{\circ} \mathrm{C}$ warming

Figure 9 shows the probability density functions at $1-10^{\circ} \mathrm{C}$, at $1{ }^{\circ} \mathrm{C}$ intervals. This reveals the same pattern as above. The information is relatively sharp within sample, but rapidly diffuses when extrapolated. At 4 and $5^{\circ} \mathrm{C}$, the PDF is still recognisably bell-shaped but there is little information beyond that.

The wide range of impact estimates for very large warming seems appropriate. These results are based on ultrapolation ${ }^{7}$ from a weak evidence base. But there is also a wide range of uncertainty about the impact of more modest warming, reflecting the literature which indeed does not agree on the sign of the impact at $2.5^{\circ} \mathrm{C}$ warming.

Figure 5 shows four alternative estimates of the survival function of the total economic impact of a $3^{\circ} \mathrm{C}$ warming. The first method uses the vote-counting PDF (cf. Fig. 1) to assign probabilities to the parabolas and hence the impact at $3^{\circ} \mathrm{C}$. This is method used in Fig. 4. The second method does not correct for the non-random sampling of parabolas. This particularly affects the 10-40 and 60-90 percentiles, as parabolas were sample in the centre and the tails. The third method uses the sample standard deviation (cf. Table 2) as prediction error, and the 14 observations. The fourth method uses the fit of the parabola to the 14 observation to estimate the prediction error. The vote-counting method leads to the widest range of uncertainty and this method is therefore used as the default. This implies that, indeed, net negative impacts are reasonably certain at $3^{\circ} \mathrm{C}$ warming.

Figure 10 compares the survival function for the impact of $2.5^{\circ} \mathrm{C}$ of warming as the derived above (i.e., based on the derivative of the $\mathrm{CDFs}$ for $1.0,2.5$ and $3.0^{\circ} \mathrm{C}$ warming) to the survival function for $2.5^{\circ} \mathrm{C}$ (see Fig. 1). Figure 10 shows that the joint survival function contains by and large the same information as a key point of calibration.

Figure 11 gives seven alternative ranges for the total economic impact of $5.0^{\circ} \mathrm{C}$ warming. At the extreme left, there is the best-fit parabola and its $99 \%$ confidence interval (from the forecast error). At the extreme right, there is the $99 \%$ confidence interval of the vote-counting PDF. The other ranges are the minimum and maximum of the five methods used to generate the set of parabolas (single/double bootstrap/fit, sample). The bootstrap and fit methods generate a range that is too narrow, while the sample method yields results that are very

7 Ultrapolation is beyond extrapolation. 

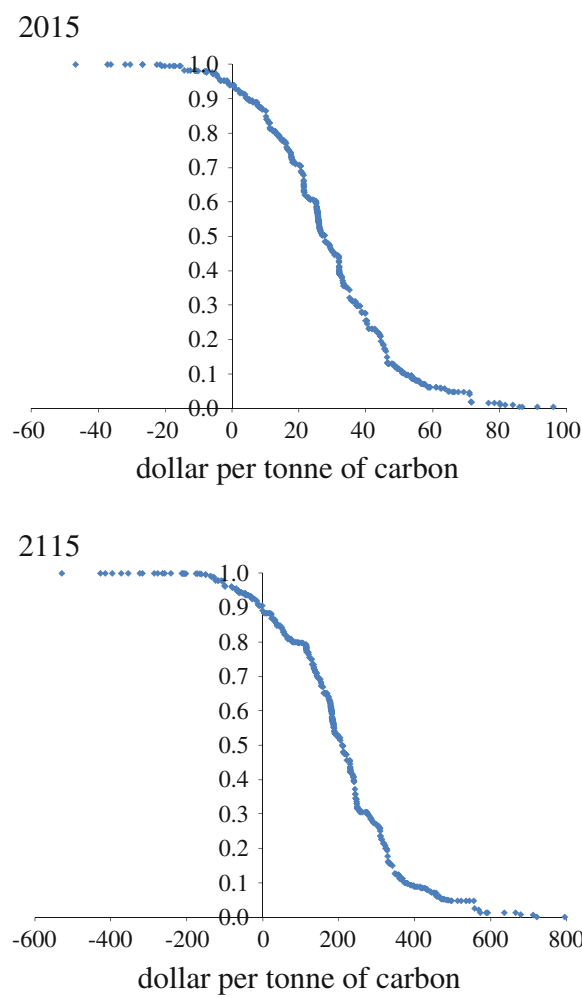
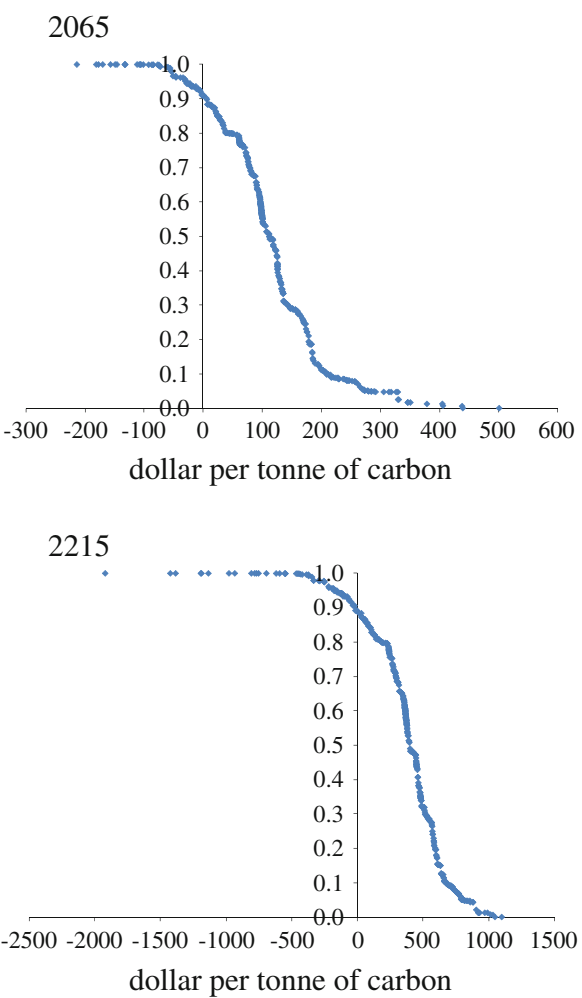

Fig. 6 The survival functions of the social cost of carbon for different points in time

far in the tail. Figure 11 also shows the averages and expectations. The vote-counting PDF, although build up from symmetric components, is skewed towards more negative impacts.

\section{Estimates of the Marginal Cost of Carbon Dioxide Emissions}

\subsection{Methods}

DICE99 (Nordhaus and Boyer 2000) is the only integrated assessment model that assumes the global economic impact of climate change is a parabolic function of the global mean surface air temperature. The model code is readily available ${ }^{8}$ and convenient in use. I therefore use DICE99 to explore the implications of the estimates of the total costs of climate change for the social cost of carbon. I use the exact same version of DICE99 as (Nordhaus and Boyer 2000), except for the parameters of the climate change impact parabola.

The 407 parabolas discussed in Sect. 3 were put in DICE99. The first partial derivative of the total impact to a change in emissions is approximated analytically in the model code. The social cost of carbon equals the discounted sum of partial derivatives, using a pure rate of time preference that starts at $2.85 \%$ per year in 2015 and gradually falls over time (to $2.20 \%$ in 2115).

8 http://www.econ.yale.edu/ nordhaus/homepage/web\%20table\%20of\%20contents\%20102599.htm. 


\subsection{Results}

The mean social cost of carbon starts at $\$ 29 / \mathrm{tC}$ in 2015 , rises to $\$ 116 / \mathrm{tC}$ in 2065 , to $\$ 208 / \mathrm{tC}$ in 2115 , and to $\$ 379 / \mathrm{tC}$ in 2215 . Figure 6 shows the survival functions at these points in time. In 2015, the uncertainty is relatively tight with $90 \%$ of the probability mass between $-\$ 1 / \mathrm{tC}$ and $\$ 65 / \mathrm{tC}$. The uncertainty appropriately widens as we look further into the future. For 2065 , the $90 \%$ confidence interval spans $-\$ 30 / \mathrm{tC}$ to $\$ 279 / \mathrm{tC}$. For 2115 , the range is from $-\$ 70 / \mathrm{tC}$ to $\$ 483 / \mathrm{tC}$. For 2215 , the $90 \%$ confidence interval of the social cost of carbon is from $-\$ 182 / \mathrm{tC}$ to $\$ 802 / \mathrm{tC}$.

The growth rate of the mean social cost of carbon over the twenty-first century is $1.99 \%$ per year. This is indistinguishable from the IPCC estimate of $2 \%$ (Yohe et al. 2007). Figure 12 shows that the uncertainty about this estimate is rather narrow. This is because the growth rate of the social cost of carbon is not just driven by the total impact of climate change (the only uncertain variable in this analysis) but also by the discount rate, the rate of degradation of carbon in the atmosphere, the rate of warming, the rate of economic growth, and the rate of emissions growth-all of which are kept constant between scenarios in the current analysis.

\section{Discussion and Conclusion}

In this paper, I survey the estimates of the total economic impacts of climate change. While climate change is initially positive, incremental impacts are negative for any warming that can be avoided. Greenhouse gas emissions are therefore a negative externality. Published estimates suggest that climate change is not a particularly large problem. However, estimates are available for a global warming of up to $3.0^{\circ} \mathrm{C}$ while actual warming may well be (much) larger than that. I combine the primary estimates to form probability density functions for the impact of $1.0,2.5$ and $3.0^{\circ} \mathrm{C}$ of warming. I use vote-counting rather than Bayesian updating so as to preserve the wide range of uncertainty. The primary estimates suggest that the impacts follow a parabola and the PDFs are used to derive the probability distribution of the parabola's parameters. This is in turn used for extrapolation. Impacts of warming of $3.0^{\circ} \mathrm{C}$ or more are most likely negative. Beyond $7.0^{\circ} \mathrm{C}$, there is a reasonable chance that climate change would imply a total loss of welfare-although the PDF is very diffuse. The uncertainty about the social cost of carbon is fairly wide too and grows over time. Although it cannot be excluded that greenhouse gas emissions should be subsidized, the expected value of the social cost of carbon points to a carbon tax that starts around $\$ 30 / \mathrm{tC}$ and rises at $2 \%$ per year.

There are a number of caveats to these results. First, I only consider the uncertainty about the economic impact of climate change. I disregard the uncertainty about climate change itself, and the uncertainty about future emissions and concentrations (Weitzman 2007, 2009). The conditional uncertainty shown in this paper necessarily underestimates the actual uncertainty. Second, I disregard changes in the vulnerability of society to climate change (Horowitz 2002; Yohe and Tol 2002). This is known to substantially modulate the impact of climate change, but as the 14 studies do not consider this, it is omitted here. Third, I fit a single functional form to the 14 primary estimates. As the 14 studies together assess only 3 scenarios of warming, a parabola is the most complex polynomial one can fit while maintaining some degrees of freedom - but that does not imply, of course, that the impact function is truly parabolic. Fourth, I use Normal distributions as the basic components of the vote-counting procedure. Although the final PDF is skewed towards the bad tail, one may argue that this should reasonably be assumed (rather than emerge). Fifth, I do not assess the policy implications. While I estimate the social cost of carbon, I do not impose a carbon tax in the model. Nor do I estimate the 
risk premium on the social cost of carbon, which could be considerable as the impact of climate change reaches a total welfare loss at greater warming. All these matters are deferred to future research.

Acknowledgments This paper benefitted from discussions with and comments by David Anthoff, Trudy Ann Cameron, Bill Cline, Sam Fankhauser, Sean Lyons, David Maddison, Rob Mendelsohn, Bill Nordhaus, Steve Pacala, David Pearce, Katrin Rehdanz, Till Requate, Joel Smith, Jeremy Stein, Timothy Taylor, John Weyant and Gary Yohe. Three anonymous referees had excellent comments on an earlier version. The ClimateCost project (CEC DG Research FP7) provided welcome financial support. All errors and opinions are mine.

Open Access This article is distributed under the terms of the Creative Commons Attribution License which permits any use, distribution, and reproduction in any medium, provided the original author(s) and the source are credited.

\section{Appendix: Additional Material}

\section{Statistical Procedures}

In the main text, three procedures are used to estimate a probability density function: sample statistics, Bayesian updating, and vote counting.

Suppose that there are $M$ estimates $X_{1}, X_{2}, \ldots, X_{M}$ of $X$. The sample mean and standard deviation are:

$$
\begin{aligned}
\mu & =\frac{1}{M} \sum_{i=1}^{M} X_{i} \\
\sigma^{2} & =\frac{1}{M-1} \sum_{i=1}^{M}\left(X_{i}-\mu\right)^{2}
\end{aligned}
$$

Based on these sample statistics, one can assume that $X$ is distributed as $\mathrm{N}\left(\mu, \sigma^{2}\right)$, where $\mathrm{N}$ denotes the Normal distribution.

This procedure, however, assumes that $X_{i}$ is known for certain. Let us assume that there is uncertainty about the primary estimates. Specifically, let us assume that these estimates are distributed as $\mathrm{N}\left(X_{i}, \sigma^{2}\right)$.

Thus, we have $M$ probability density functions. In Bayesian updating, we take one observation as the prior, and the other $M-1$ as observations that update the prior belief. Because each of the distributions is Normal, the result is again a Normal distribution, with characteristics

$$
\begin{aligned}
\lambda & =\tau^{2} \sum_{i=1}^{M} \frac{X_{i}}{\sigma_{i}^{2}}=\tau^{2} \sum_{i=1}^{M} \frac{X_{i}}{\sigma^{2}}=\frac{\tau^{2}}{\sigma^{2}} \sum_{i=1}^{M} X_{i}=\frac{1}{M} \sum_{i=1}^{M} X_{i}=\mu \\
\tau^{2} & =1 / \sum_{i=1}^{M} \frac{1}{\sigma_{i}^{2}}=1 / \sum_{i=1}^{M} \frac{1}{\sigma^{2}}=\frac{\sigma^{2}}{M}
\end{aligned}
$$

Equivalently, Bayesian updating assumes that

$$
P^{B}(Y<X<Y+\delta) \propto \prod_{i=1}^{M} P\left(Y<X_{i}<Y+\delta\right)
$$

That is, Bayesian updating multiplies the individual probability density functions (and rescales to integrate to unity). Therefore, if a particular outcome is unlikely according to any 
of the individual probability density functions, it is unlikely according to the joint probability density function. Indeed, Eq. (A5) shows that the standard deviation shrinks with the square root of the number of observations.

Vote-counting avoids this rapid narrowing of uncertainties. Conceptually, the individual probability density functions are taken as votes for the true value, and the average vote is used. Mathematically,

$$
P^{V}(Y<X<Y+\delta) \propto \sum_{i=1}^{M} P\left(Y<X_{i}<Y+\delta\right)
$$

Table 2 Observed and extrapolated estimates of the total economic impact of climate change, their mean and (standard deviation), and selected percentiles of the vote-counting PDF

\begin{tabular}{lccc}
\hline & $1.0^{\circ} \mathrm{C}$ & $2.5^{\circ} \mathrm{C}$ & $3.0^{\circ} \mathrm{C}$ \\
\hline Tol 02 & 2.30 & -0.75 & -3.51 \\
Rehdanz & -0.40 & -1.33 & -1.72 \\
Fankhauser & 0.88 & -1.40 & -3.12 \\
Tol 95 & 0.48 & -1.90 & -3.52 \\
Yang & 0.64 & -1.70 & -3.36 \\
Plambeck & 0.00 & -2.50 & -4.00 \\
Mendelsohn & 2.00 & 0.00 & -2.00 \\
Mendelsohn & 2.08 & 0.10 & -1.92 \\
Boyer & 0.80 & -1.50 & -3.20 \\
Maddison & 1.92 & -0.10 & -2.08 \\
Hope & 2.72 & 0.90 & -1.28 \\
Nordhaus 06 & 2.72 & 0.90 & -1.28 \\
Nordhaus $94 \mathrm{~b}$ & 0.23 & -0.67 & -1.30 \\
Nordhaus $94 \mathrm{a}$ & 2.54 & -1.41 & -4.80 \\
Primary & 0.95 & -0.90 & -3.05 \\
$\mathrm{~N}=2,10,2$ & $(1.91)$ & $(1.08)$ & $(2.47)$ \\
Sample & 1.25 & -0.94 & -2.75 \\
$\mathrm{~N}=14$ & $(1.01)$ & $(0.92)$ & $(1.06)$ \\
Bayesian & 1.25 & -0.94 & -2.75 \\
$\mathrm{~N}=14$ & $(0.27)$ & $(0.25)$ & $(0.28)$ \\
Vote-counting & 1.25 & -0.94 & -2.75 \\
$\mathrm{~N}=14$ & $(1.40)$ & $(1.28)$ & $(1.48)$ \\
$1 \%$ & -1.90 & -3.75 & -6.17 \\
$5 \%$ & -1.05 & -2.96 & -5.21 \\
$10 \%$ & -0.58 & -2.53 & -4.68 \\
$33 \%$ & 0.59 & -1.49 & -3.41 \\
$50 \%$ & 1.25 & -0.93 & -2.73 \\
$67 \%$ & 1.91 & -0.35 & -2.06 \\
$90 \%$ & 3.07 & 0.76 & -0.85 \\
$95 \%$ & 3.54 & 1.23 & -0.37 \\
$99 \%$ & 4.36 & 2.08 & 0.50 \\
\hline & & & \\
\hline & & & \\
\hline
\end{tabular}


That is, vote-counting adds the individual probability density functions (and rescales to integrate to unity). With vote-counting, each individual probability density function receives a weight of $1 / M$.

With normal distributions, Eq. (A6) cannot be solved analytically.

See Table 2 and Figs. 7, 8, 9, 10, 11, 12.

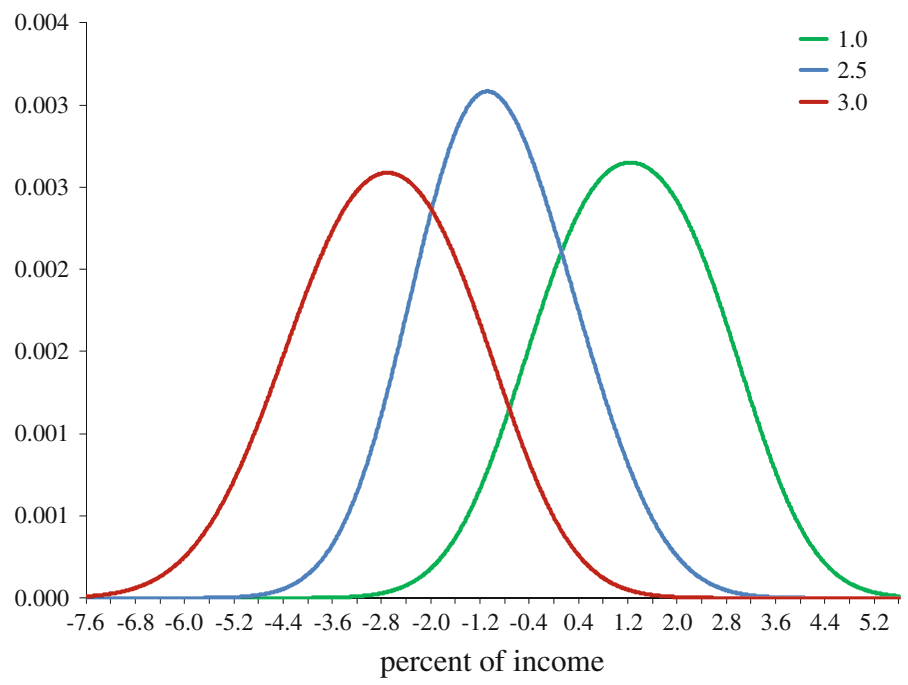

Fig. 7 The probability density function of the total economic impact of $1.0,2.5$ and $3.0^{\circ} \mathrm{C}$ of warming

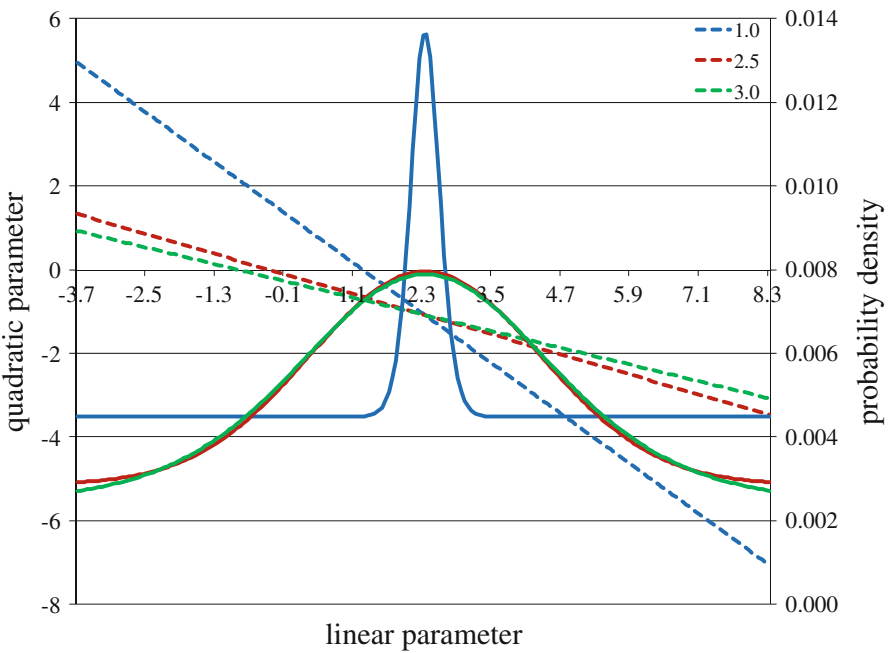

Fig. 8 The most likely quadratic parameter as a function of the linear parameter for three alternative calibration points $\left(1.0,2.5\right.$ and $\left.3.0^{\circ} \mathrm{C}\right)$, and the conditional probability of the linear and quadratic parameters according to the bivariate probability density function of Fig. 2; note that the vote-counting procedure implies that there is a constant, minimum probability (visible for $1.0^{\circ} \mathrm{C}$ only) of the calibration line 

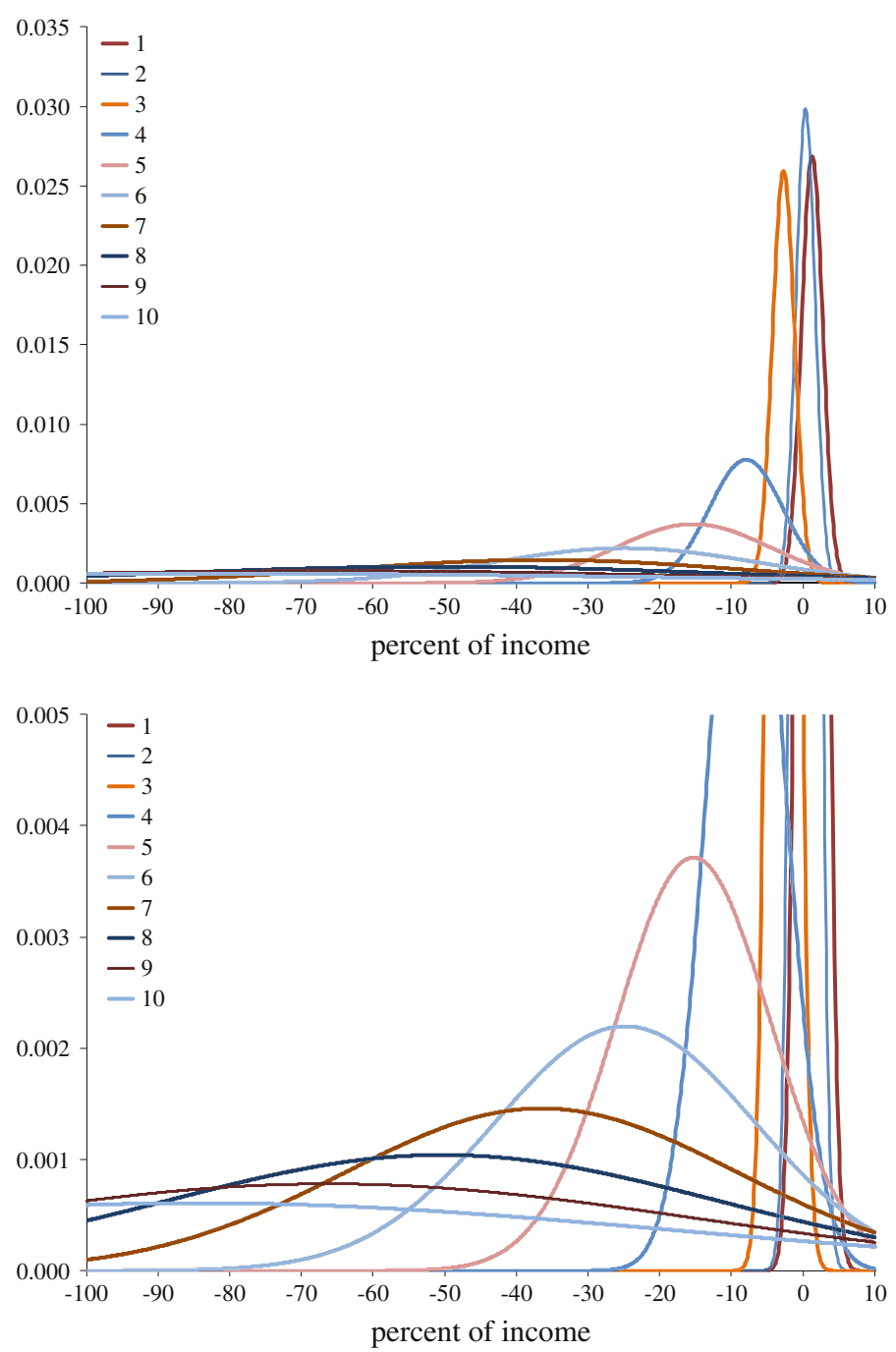

Fig. 9 The probability density functions of $1-10^{\circ} \mathrm{C}$ warming at $1^{\circ} \mathrm{C}$ intervals. The top and bottom graph are identical except for the scale of the vertical axis 


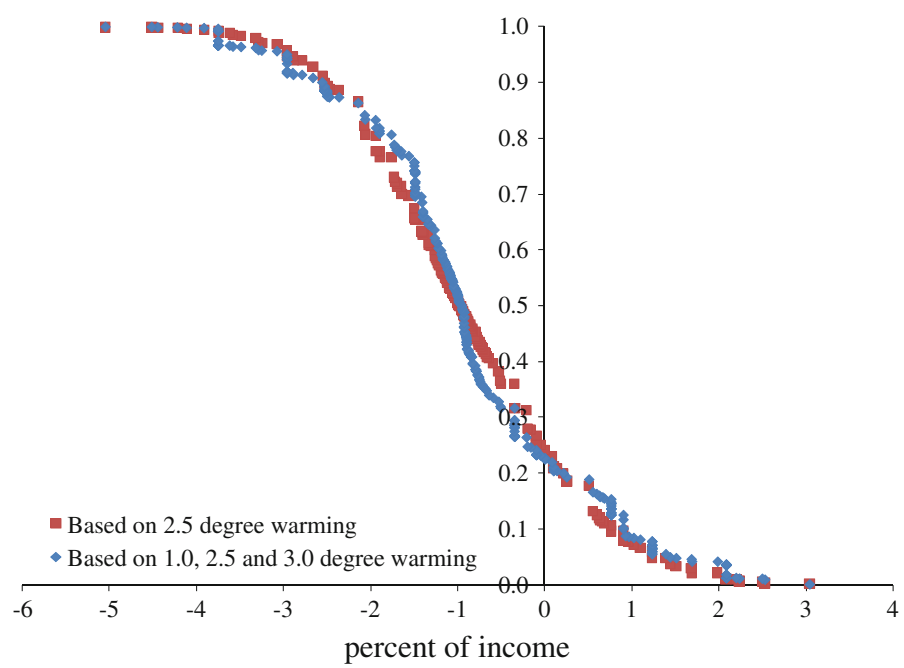

Fig. 10 Four alternative survival functions for the total economic impact of $3^{\circ} \mathrm{C}$ warming

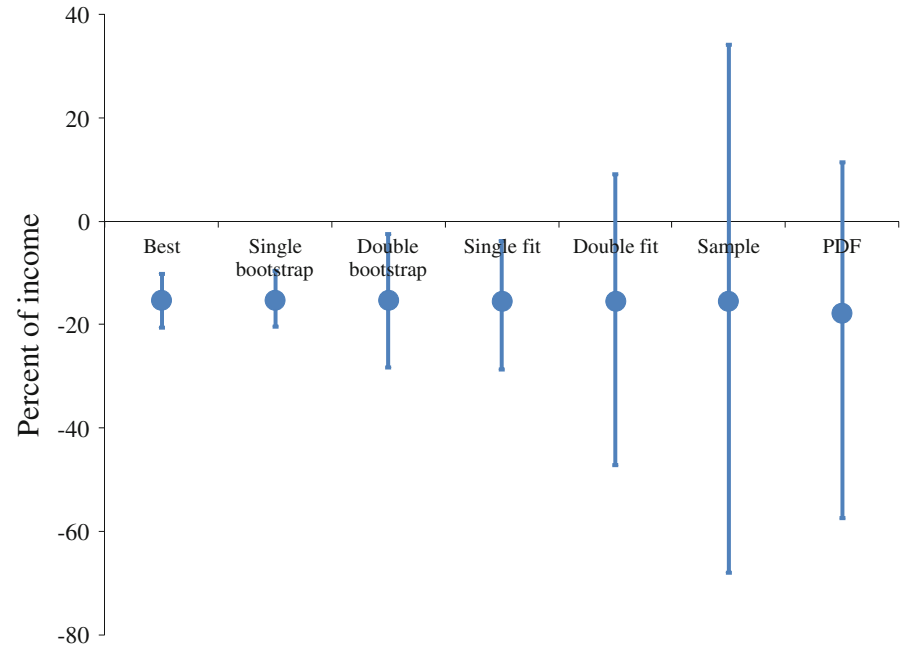

Fig. 11 Alternative ranges of impact estimates for $5.0^{\circ} \mathrm{C}$ warming 


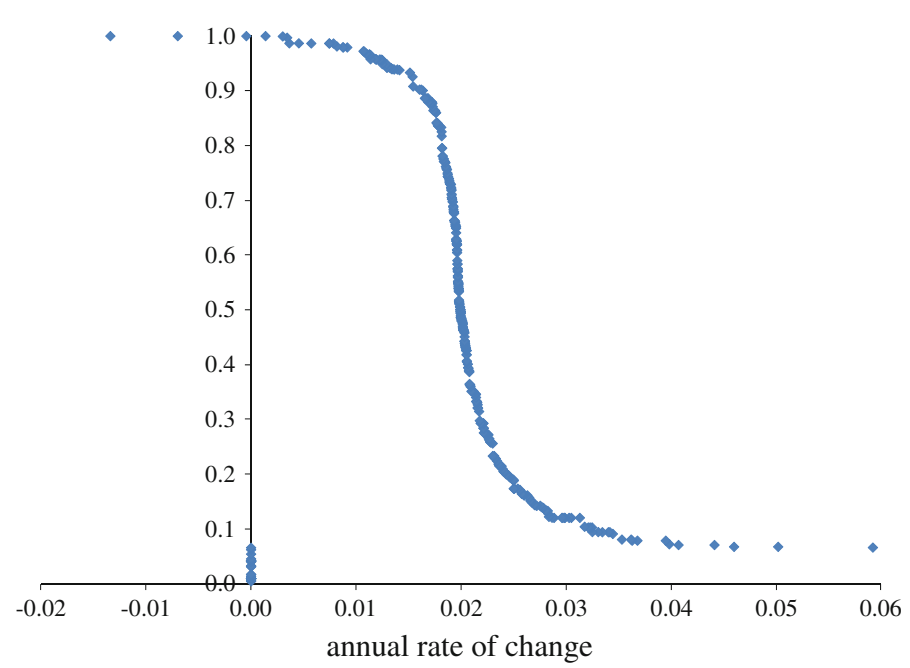

Fig. 12 The survival function of the growth rate of the social cost of carbon over the twenty-first century

\section{References}

Brouwer R, Spaninks FA (1999) The validity of environmental benefits transfer: further empirical testing. Environ Res Econ 14(1):95-117

Clarke L, Edmonds J, Krey V, Richels R, Rose S, Tavoni M (2009) International climate policy architectures: overview of the EMF 22 international scenarios. Energy Econ 31(S2):S64-S81

Fankhauser S (1994) The economic costs of global warming damage: a survey. Glob Environ Change 4(4):301-309

Fankhauser S (1995) Valuing climate change-the economics of the greenhouse, 1st edn. EarthScan, London

Freeman MC, Groom B (2010) Gamma discounting and the combination of forecasts. Soc Sci Res Netw. http://ssrn.com/abstract=1676793

Hope CW (2006) The marginal impact of CO2 from PAGE2002: an integrated assessment model incorporating the IPCC's five reasons for concern. Integr Assess J 6(1):19-56

Horowitz JK (2002) Preferences in the future. Environ Res Econ 21:241-259

Long SP, Ainsworth EA, Leakey ADB, Noesberger J, Ort DR (2006) Food for thought: lower-than-expected crop yield stimulation with rising CO2 concentrations. Science 312(5811):1918-1921

Maddison DJ (2003) The amenity value of the climate: the household production function approach. Res Energy Econ 25(2):155-175

Mendelsohn RO, Morrison WN, Schlesinger ME, Andronova NG (2000a) Country-specific market impacts of climate change. Clim Change 45(3-4):553-569

Mendelsohn RO, Schlesinger ME, Williams LJ (2000b) Comparing impacts across climate models. Integr Assess 1(1):37-48

Nordhaus WD (1994a) Expert opinion on climate change. Am Sci 82(1):45-51

Nordhaus WD (1994b) Managing the global commons: the economics of climate change. The MIT Press, Cambridge

Nordhaus WD (2006) Geography and macroeconomics: new data and new findings. Proc Natl Acad Sci 103(10):3510-3517

Nordhaus WD, Boyer JG (2000) Warming the world: economic models of global warming. The MIT Press, Cambridge, MA

Nordhaus WD, Yang Z (1996) RICE: A regional dynamic general equilibrium model of optimal climatechange policy. Am Econ Rev 86(4):741-765

Plamberk EL, Hope CW (1996) PAGE95-An updated valuation of the impacts of global warming. Energy Policy 24(9):783-793

Rehdanz K, Maddison DJ (2005) Climate and happiness. Ecol Econ 52(1):111-125

Smith JB, Schellnhuber H-J, Mirza MQ, Fankhauser S, Leemans R, Erda L, Ogallo L, Pittock AB, Richels RG, Rosenzweig C, Safriel U, Tol RSJ, Weyant JP, Yohe GW (2001) Vulnerability to climate change and 
reasons for concern: a synthesis. In: McCarthy JJ (ed) et al Climate change 2001: impacts, adaptation, and vulnerability. Press Syndicate of the University of Cambridge, Cambridge, UK pp 913-967

Stern NH, Peters S, Bakhski V, Bowen A, Cameron C, Catovsky S, Crane D, Cruickshank S, Dietz S, Edmondson N, Garbett S-L, Hamid L, Hoffman G, Ingram D, Jones B, Patmore N, Radcliffe H, Sathiyarajah R, Stock M, Taylor C, Vernon T, Wanjie H, Zenghelis D (2006) Stern review: the economics of climate change. Cambridge University Press, Cambridge

Tol RSJ (1995) The damage costs of climate change toward more comprehensive calculations. Environ Res Econ 5(4):353-374

Tol RSJ (2002a) Estimates of the damage costs of climate change-Part 1: Benchmark estimates. Environ Res Econ 21(1):47-73

Tol RSJ (2002b) Estimates of the damage costs of climate change-Part II: Dynamic estimates. Environ Res Econ 21(2):135-160

Tol RSJ (2005) The marginal damage costs of carbon dioxide emissions: an assessment of the uncertainties. Energy Policy 33:2064-2074

Tol RSJ (2008) The social cost of carbon: trends, outliers and catastrophes. Econ Open-Access Open-Assess E-Journal 2(25):1-24

Tol RSJ (2009) The economic effects of climate change. J Econ Perspect 23(2):29-51

Tol RSJ (2010) The economic impact of climate change. Perspektiven der Wirtschaftspolitik 11(suppl 1): 13-37

Weitzman ML (2007) A review of the Stern review on the economics of climate change. J Econ Lit 45(3): $703-724$

Weitzman ML (2009) On modelling and interpreting the economics of catastrophic climate change. Rev Econ Stat 91(1):1-19

Yohe GW, Lasco RD, Ahmad QK, Arnell NW, Cohen SJ, Hope CW, Janetos AC, Perez RT (2007) Perspectives on climate change and sustainability. In: Parry ML (ed) et al Climate change 2007: impacts, adaptation and vulnerability - contribution of working ii to the fourth assessment report on the intergovernmental panel on climate change. Cambridge University Press, Cambridge pp 811-841

Yohe GW, Tol RSJ (2002) Indicators for social and economic coping capacity-moving towards a working definition of adaptive capacity. Glob Environ Change 12(1):25-40 